\title{
BMJ Open Facilitation roles and characteristics associated with research use by healthcare professionals: a scoping review
}

\author{
Lisa A Cranley, ${ }^{1}$ Greta G Cummings, ${ }^{2}$ Joanne Profetto-McGrath, ${ }^{2}$ Ferenc Toth, ${ }^{2}$ \\ Carole A Estabrooks ${ }^{2}$
}

To cite: Cranley LA, Cummings GG, ProfettoMcGrath J, et al. Facilitation roles and characteristics associated with research use by healthcare professionals: a scoping review. BMJ Open 2017;7:e014384. doi:10.1136/ bmjopen-2016-014384

- Prepublication history and additional material for this paper are available online. To view these files please visit the journal online (http://dx.doi. org/10.1136/bmjopen-2016014384).

Received 21 September 2016 Revised 30 December 2016 Accepted 21 February 2017

\section{CrossMark}

${ }^{1}$ Lawrence S. Bloomberg Faculty of Nursing, University of Toronto, Toronto, Canada

${ }^{2}$ Faculty of Nursing, University of Alberta, Edmonton, Canada

Correspondence to

Dr Lisa A Cranley;

lisa.cranley@utoronto.ca

\begin{abstract}
Background Implementing research findings into practice is a complex process that is not well understood. Facilitation has been described as a key component of getting research findings into practice. The literature on facilitation as a practice innovation is growing. This review aimed to identify facilitator roles and to describe characteristics of facilitation that may be associated with successful research use by healthcare professionals. Methods We searched 10 electronic databases up to December 2016 and used predefined criteria to select articles. We included conceptual papers and empirical studies that described facilitator roles, facilitation processes or interventions, and that focused on healthcare professionals and research use. We used content and thematic analysis to summarise data. Rogers' five main attributes of an innovation guided our synthesis of facilitation characteristics.
\end{abstract}

Results Of the 38488 articles identified from our online and manual search, we included 195 predominantly research studies. We identified nine facilitator roles: opinion leaders, coaches, champions, research facilitators, clinical/practice facilitators, outreach facilitators, linking agents, knowledge brokers and external-internal facilitators. Fifteen facilitation characteristics were associated with research use, which we grouped into five categories using Rogers' innovation attributes: relative advantage, compatibility, complexity, trialability and observability.

Conclusions We found a diverse and broad literature on the concept of facilitation that can expand our current thinking about facilitation as an innovation and its potential to support an integrated, collaborative approach to improving healthcare delivery.

\section{INTRODUCTION}

Scholars describe the potential for evidencebased decision making to have a positive impact on patient outcomes. ${ }^{1}$ Implementing evidence (ie, research findings) into practice is a complex, multifaceted process that requires a proactive effort to encourage use at the point of decision making. ${ }^{2-4}$ Multilevel factors influence this implementation ${ }^{5}$; some
Strengths and limitations of this study

- This study provides a comprehensive scoping review of a diverse literature of facilitator roles and characteristics of facilitation from various disciplines.

- Arksey and 0'Malley's (2005) framework was used to guide the scoping review process.

- Grey literature was not included, nor did we conduct a quality appraisal of included studies as this is not part of a scoping review undertaking, and this may introduce the potential for publication bias. However, the scoping review enabled us to synthesise the breadth of literature that characterises the quantity, nature and extent of research evidence on facilitation and the roles undertaken to facilitate the uptake of evidence.

of these include individual (eg, education, attitude) ${ }^{6-8}$ organisational/contextual, ${ }^{9-14}$ system $^{14}$ and innovation-specific factors. ${ }^{15}$ Several knowledge translation (KT) theories exist that can be used to guide the process of getting research evidence into practice. ${ }^{16}$ In their Promoting Action on Research Implementation in Health Services (PARiHS) framework, Kitson and colleagues ${ }^{17}$ highlighted the importance of facilitation that, along with strong evidence and a context supportive of change, can lead to successful research implementation. Facilitation is a technique where an individual makes things easier for others, by providing support to help them change their ways of thinking and working. ${ }^{17}$ In their refined integrated framework i-PARiHS, facilitation is an active element that integrates the other core constructs: innovation, recipients and context. ${ }^{18}$

In the healthcare literature, a small body of conceptual work on facilitation has considered it a promising approach to implementing evidence into practice. ${ }^{17-21}$ Facilitation has 
evolved from a concept in the education and counselling literature ${ }^{22}$ to an implementation intervention in the healthcare and KT literature ${ }^{3420}$ and has recently been situated in the organisational learning theory literature. ${ }^{23}$ The literature on facilitation roles and characteristics is growing. ${ }^{19}$ Thompson and colleagues delineated the similarities and differences between five roles that aim to influence a practice or behaviour change: opinion leader, facilitator, champion, linking agent and change agent, noting much ambiguity remains among these roles. ${ }^{24}$ Harvey and colleagues explored the purpose, roles, skills and attributes of facilitators, suggesting that the concept of facilitation is only partially developed. ${ }^{20}$ Dogherty et al updated Harvey et al $\mathrm{s}^{20}$ literature review and reported that, in addition to facilitation as role and process, project management and leadership were important components of facilitation. ${ }^{19}$

Two reviews have been conducted specifically on practice facilitation, also described as outreach facilitation, where facilitators assist primary care physicians with research implementation and quality improvement projects. ${ }^{25}{ }^{26}$ These studies found that practice facilitators were effective in improving practice processes and patient care outcomes, ${ }^{25}$ and primary care physicians were almost three times more likely to adopt evidencebased guidelines with practice facilitation. ${ }^{26}$ Although some preliminary evidence supports practice facilitation as an effective intervention to implement evidence into practice, facilitation as a construct requires further development and testing for its effectiveness in improving outcomes.

Implementation methods-such as facilitation-can be viewed as practice innovations. Rogers defined an innovation as an idea or practice that is perceived as new by an individual. ${ }^{15} \mathrm{He}$ described five main attributes of an innovation: (1) relative advantage-the perception that an innovation is better or more beneficial than existing practice; (2) high compatibility-the perception that the innovation is consistent with existing values, beliefs and needs; (3) low complexity-the perception that the innovation is easy to understand and use; (4) trialability-the opportunity to try the innovation before making a decision about its adoption; and (5) observability-the extent to which the effects of the innovation are observed and communicated to others. ${ }^{15}$ Innovations with all of these qualities tend to be adopted more rapidly than other innovations. ${ }^{15}$

By treating facilitation as an innovation and healthcare providers as potential adopters, we can better understand how the roles and characteristics of facilitation may contribute to successfully implementing research into practice. Our review complements and extends the review by Dogherty et $a l^{27}$ which explored elements of facilitation based on an existing systematic review of the effectiveness of interventions to increase the use of practice guidelines in nursing. Our study adds to the evidence base on facilitation by describing the various roles and the characteristics of facilitation from the healthcare and management literature in the context of healthcare professionals that includes practice guidelines and other forms of research use, and the roles undertaken to facilitate the uptake of evidence. The research questions guiding this scoping review were:

1. What are the key facilitator roles identified in the literature?

2. What characteristics of facilitation contribute to research use by healthcare professionals?

\section{METHODS}

We conducted a scoping review of the literature using Arksey and O'Malley's framework to guide our review. ${ }^{28}$ Their scoping review framework has five stages: (1) identifying the research question; (2) identifying relevantstudies; (3) study selection; (4) charting the data; (5) collating, summarising and reporting the results; and an optional stage of a consultation exercise with stakeholders. ${ }^{28} \mathrm{We}$ searched the following 10 electronic databases from the healthcare and management literature: ABI Inform (1970-2016), Business Source Complete (1886-2016), CINAHL (1982-2016), Cochrane Library (2003-2016), EBMR (1991-2016), Embase (1980-2016), Medline (in process and other non-indexed citations) (1950-2016), PsycINFO (1806-2016), Scopus (1960-2016) and Web of Science (1900-2016). We developed our search strategy with a research librarian who constructed expert searches tailored to each of the databases searched (box 1). Key terms and final search strategies were refined based on initial search results. For example, because our initial search revealed a large number of articles we decided not to search grey (unindexed) literature such as conference proceedings, dissertations, editorials and government reports. We manually searched reference lists of included papers to identify additional studies.

\section{Selection criteria}

We included conceptual papers and empirical studies both quantitative and qualitative that met the following criteria: (1) facilitator roles, characteristics, facilitation processes and/or interventions were described; (2) facilitation focused on healthcare providers; and (3) facilitation focused on research use in practice. We excluded: non-English literature; $;^{i}$ study protocols; articles that focused solely on facilitation directed towards patients; articles focused solely on computerised/automated reminder systems or decision support systems.

\section{Selection process}

Three team members independently screened one-third of the references for inclusion. Because of the volume of search results, we first excluded references based on

\footnotetext{
${ }^{\mathrm{i}}$ Non-English papers with English abstracts were kept if they met the abstract level inclusion criteria during the abstract screening. This was to determine the extent of the literature published in other languages. However, as we did not have the capacity to translate articles, these were not included in data extraction or analysis.
} 


\section{Box 1 Example of search strategy: Medline}

\section{Search terms}

1. (facilitator* or facilitative or facilitation).tw.

2. facilitat*.ti. or reminder systems/

3. (academic detail* or educational outreach worker* or opinion leader* or change agent* or champion* or linking agent* or promotor $^{\star}$ or knowledge broker* or enabler* or enabling or boundary spanner* or coach $\left.{ }^{\star}\right)$.tw.

4. or $/ 1-3$

5. evidence-based practice/ or evidence-based dentistry/ or evidence-based medicine/ or evidence-based emergency medicine/ or evidence-based nursing/

6. (ebp or ebm or ebn or $\mathrm{cpg}^{\star}$ or best practice $\left.{ }^{\star}\right)$.tw.

7. (evidence adj2 practice*).tw.

8. (guideline* adj2 (implement* or adher*)).tw.

9. guideline adherence/ or quality assurance, health care/ or benchmarking/ or guidelines as topic/ or practice guidelines as topic/

10. (quality adj1 (improv* or manag*)).tw.

11. 'diffusion of innovation'/ or technology transfer/

12. (research adj2 ('use' or utili?* or adopt* or implement* or disseminat* $^{*}$ or uptake or transfer* or translat* or support)).tw.

13. (knowledge adj2 ('use' or utili?* or adopt* or implement* or disseminat* $^{\star}$ or uptake or transfer* or translat ${ }^{\star}$ or support)).tw.

14. (evidence adj2 ('use' or utili?* or adopt* or implement* or disseminat $^{\star}$ or uptake or transfer* or translat* ${ }^{\star}$ or support)).tw.

15. (innovation adj2 adopt*).tw.

16. or $/ 5-15$

17. 4 and 16

18. facilitat*.mp.

19. 18 not 17

20. 'outcome and process assessment (health care)'/ or 'outcome assessment (health care)'/ or treatment outcome/ or 'process assessment (health care)"/

21. quality assurance, health care/ or benchmarking/

22. Quality Control/

23. 'Delivery of Health Care'/og [Organization \& Administration]

24. og.fs.

25. or $/ 20-24$

26. 19 and 16 and 25

27. 17 or 26

28. (comment or editorial or letter or news or newspaper article).pt.

29. 27 not 28

irrelevant titles and abstracts. Approximately $10 \%$ of articles were screened together for training and reliability. The team met periodically prior to and during screening to ensure consistency between reviewers.

\section{Data charting}

We developed a data dictionary detailing information to collect, for consistency between reviewers throughout charting. Each reviewer was assigned one-third of the included articles and extracted the following data elements: citation, purpose, theoretical framework, study design/method, sample and setting, description of facilitation role, characteristics, process and/ or intervention. We did not appraise the quality of data
Table 1 Search results

\begin{tabular}{lr} 
Database & Search results \\
\hline ABI Inform & 1710 \\
Business Source Complete & 2100 \\
CINAHL & 2539 \\
Cochrane Library & 2 \\
EBMR Central & 161 \\
Embase & 10453 \\
Medline including Medline in process & 7777 \\
PsyclNFO & 3278 \\
Scopus & 5661 \\
Web of Science & 4807 \\
Total & 38488 \\
\hline
\end{tabular}

extracted as the aim of the scoping review was to identify facilitator roles and characteristics of facilitation from the literature.

\section{Data analysis and synthesis}

We conducted a content analysis of extracted data to identify facilitator roles and characteristics of facilitation. Next, we conducted a thematic analysis using extracted data to further identify characteristics of facilitation. Because we conceptualised facilitation as an innovation, in the final analytical step, we used Rogers' attributes of an innovation as a framework to first sort and then to synthesise within each category our identified characteristics of facilitation. ${ }^{15}$ We did not report literature review papers that included studies cited in our scoping review in our roles or attributes results tables to avoid duplication.

\section{Stakeholder consultation}

We consulted with stakeholders early in analysis to inform and validate findings. ${ }^{28}$ Our decision-maker partner (CC) arranged for two study team members to meet with seven regional managers from a large healthcare organisation for feedback on the identified facilitator roles. These managers provided feedback on understandability, meaningfulness, and usefulness and relevance to practice of the facilitator roles.

\section{RESULTS}

Our searches found a combined total of 38488 references (table 1). After removing duplicates and adding 18 articles from our manual search, we screened 26593 articles and identified 791 as potentially relevant. Of these, 195 met our selection criteria and were included in our review (figure 1). We report characteristics of included studies (see online supplementary file 1), followed by facilitator roles (table 2) and characteristics (attributes) of facilitation (table 3 ). 


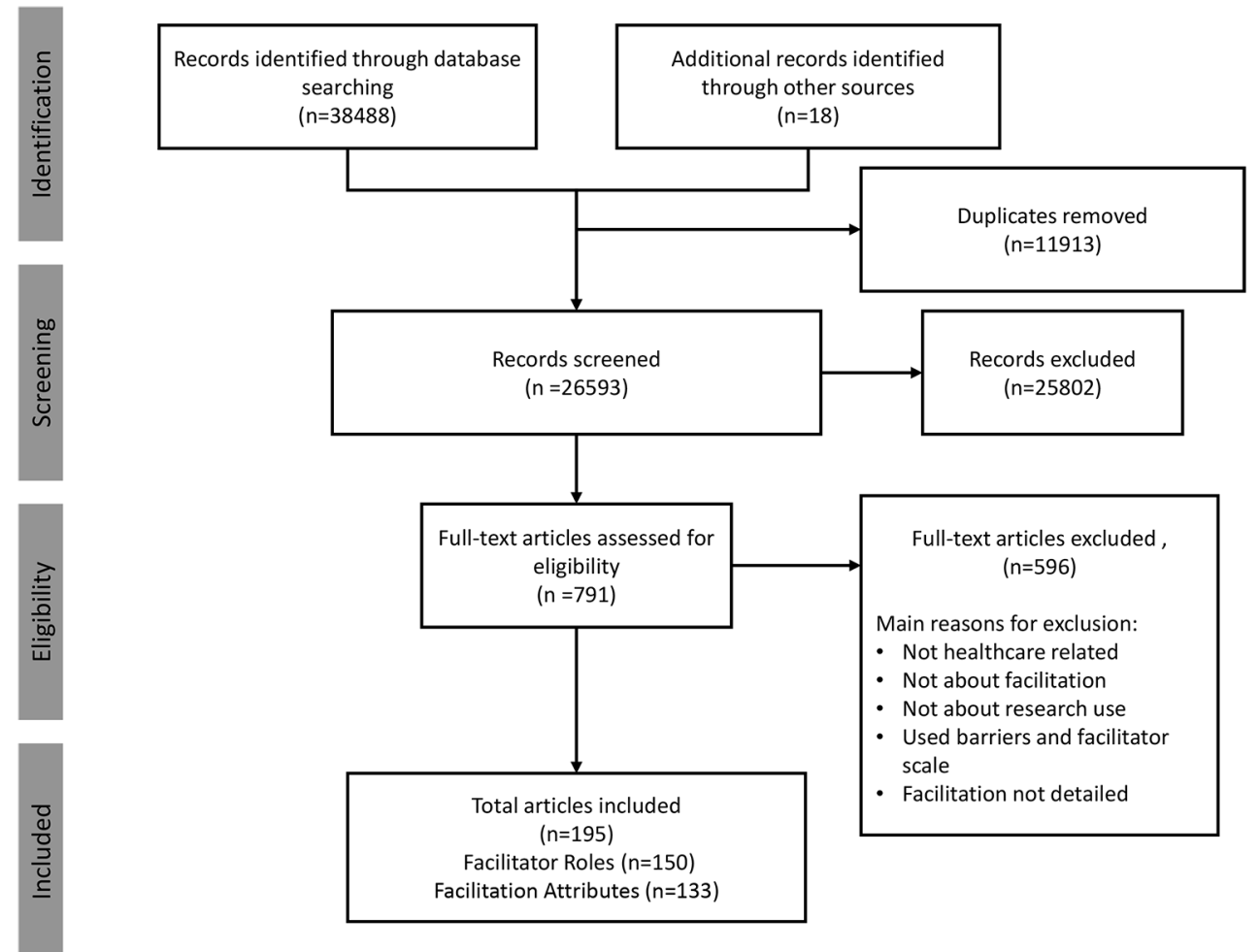

Figure 1 Screening process.

\section{Characteristics of included studies}

Our sample included 130 primary research articles: quantitative $(n=63)$, qualitative $(n=39)$ and mixed methods $(n=28)$ (used both qualitative and quantitative data collection methods). The remainder were descriptive papers $(n=34)$, literature reviews $(n=20)$ and theoretical/ conceptual papers $(n=11)$.

Over half of the research studies $(n=85 / 130)$ included a mix of healthcare providers in their samples (eg, nurses and physicians); the remainder included a single healthcare provider group. Study setting was reported in 120 studies; the most frequent were hospitals $(34 \%)$, primary care $(23 \%)$ and other community-based facilities (18\%). Less frequently cited were studies with more than one setting $(13 \%)$, long-term care $(8 \%)$, home care $(2 \%)$ and symposiums $(2 \%)$. For studies that also reported the country $(n=120)$, most were conducted in the USA (29\%), Canada (23\%), UK (18\%), Europe (10\%) and Australia (9\%). Some studies included more than one country (6\%). A few studies were conducted in Africa $(3 \%)$ and one in Singapore (1\%) and Nicaragua (1\%).

Nine definitions of facilitation were used (table 4). The definitions of facilitation from the PARiHS framework were the most frequently cited $(n=19)$. A common thread in seven of the nine definitions is that facilitation is viewed as a process of providing support to enable change to occur. 4171820 29-31 The other two definitions were notably different as they did not include process in their definitions. One article focused on relationships, ${ }^{32}$ the personal contact and support required, while the other article highlighted facilitation as a strategy for learning. ${ }^{33}$
In 77/195 articles, a theory or conceptual framework(s) guided research or contextualised findings. Most frequently cited were the PARiHS framework ${ }^{17}$ $(n=16)$, change theories (eg, Lewin's theory of change $)^{34}$ $(n=10)$ and Rogers' diffusion of innovation theory ${ }^{15}$ $(n=10)$. Sixteen papers used more than one theory or framework. ${ }^{435-49}$ For example, papers citing the PARiHS framework had used it to: inform the decision to involve both external and internal facilitators ${ }^{41}$; conceptualise a nurse pain champion role ${ }^{40}$; guide design of a KT intervention for continuous improvement of patient care and evidence-based practice (EBP) ${ }^{38}$; and assist with the description of processes and outcomes of an EBP training programme. ${ }^{50}$ Examples of other frameworks used are Donabedian's structure, process, outcome model ${ }^{37}$ 51-54; Graham et al $\mathrm{s}^{55}$ Knowledge to Action Framework ${ }^{41485657}$; and May et $a l \mathrm{~s}^{58}$ Normalization Process Theory. ${ }^{59}$

\section{Facilitator roles}

We identified nine facilitator roles: opinion leaders, coaches, champions, research facilitators, clinical/practice facilitators, outreach facilitators, linking agents, knowledge brokers and external-internal facilitators. Of note, overlap exists in the terms used to describe a clinical facilitator and a practice facilitator, and a practice facilitator and outreach facilitator. We describe conditions under which each role is considered most appropriate based on locality (facilitators located internal to the organisation, external, or combined external and internal) and formality (formal appointed role vs informal role). These nine facilitator roles expand (both in number and scope) those 


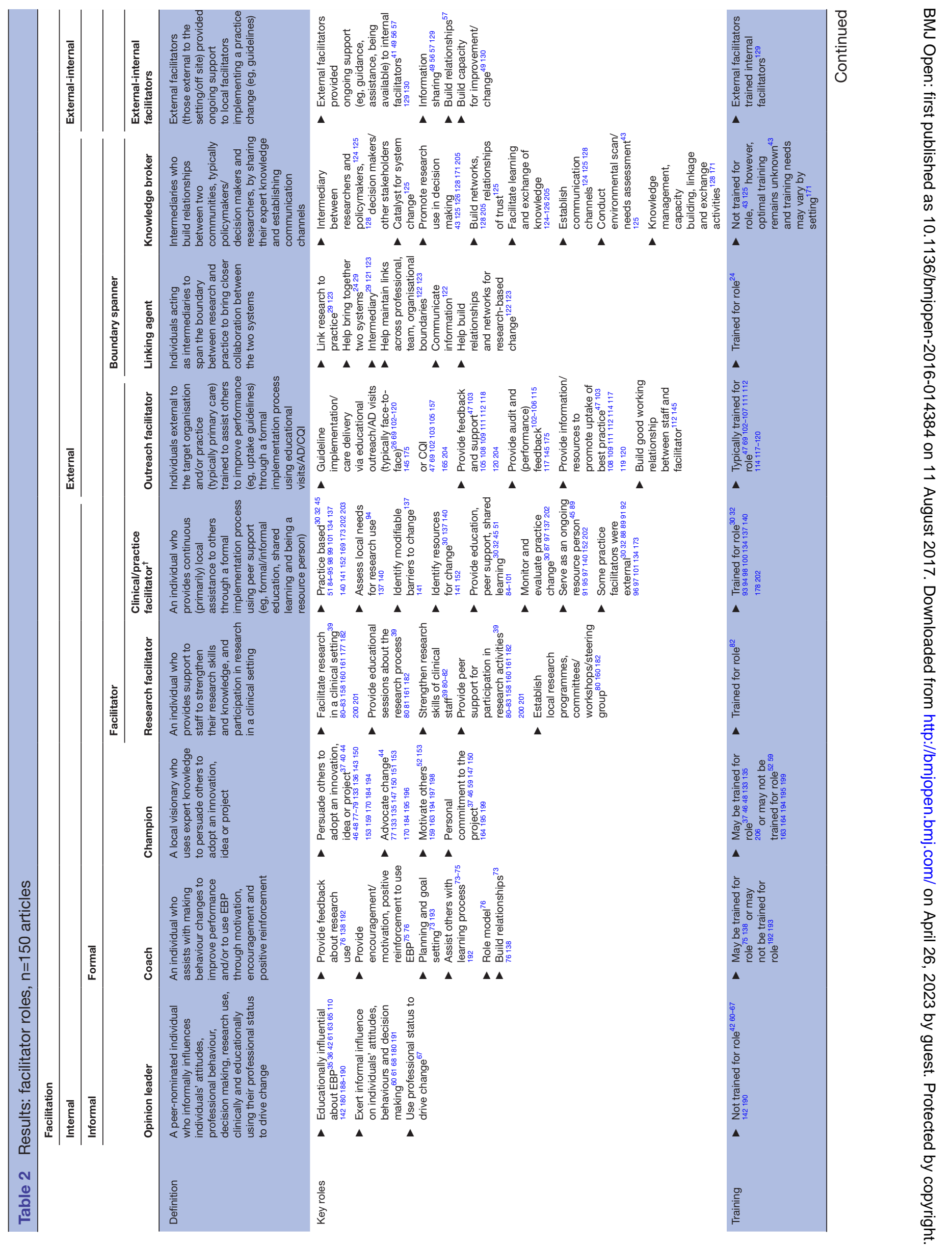




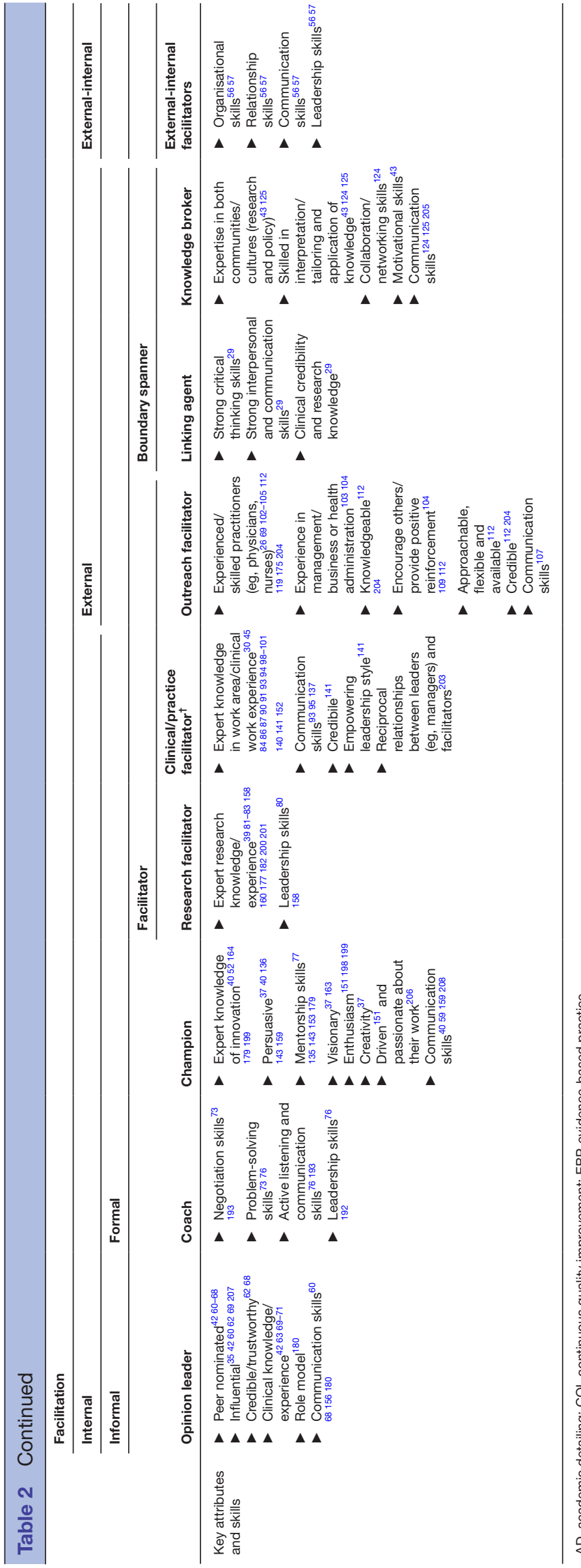

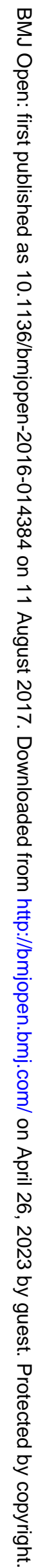




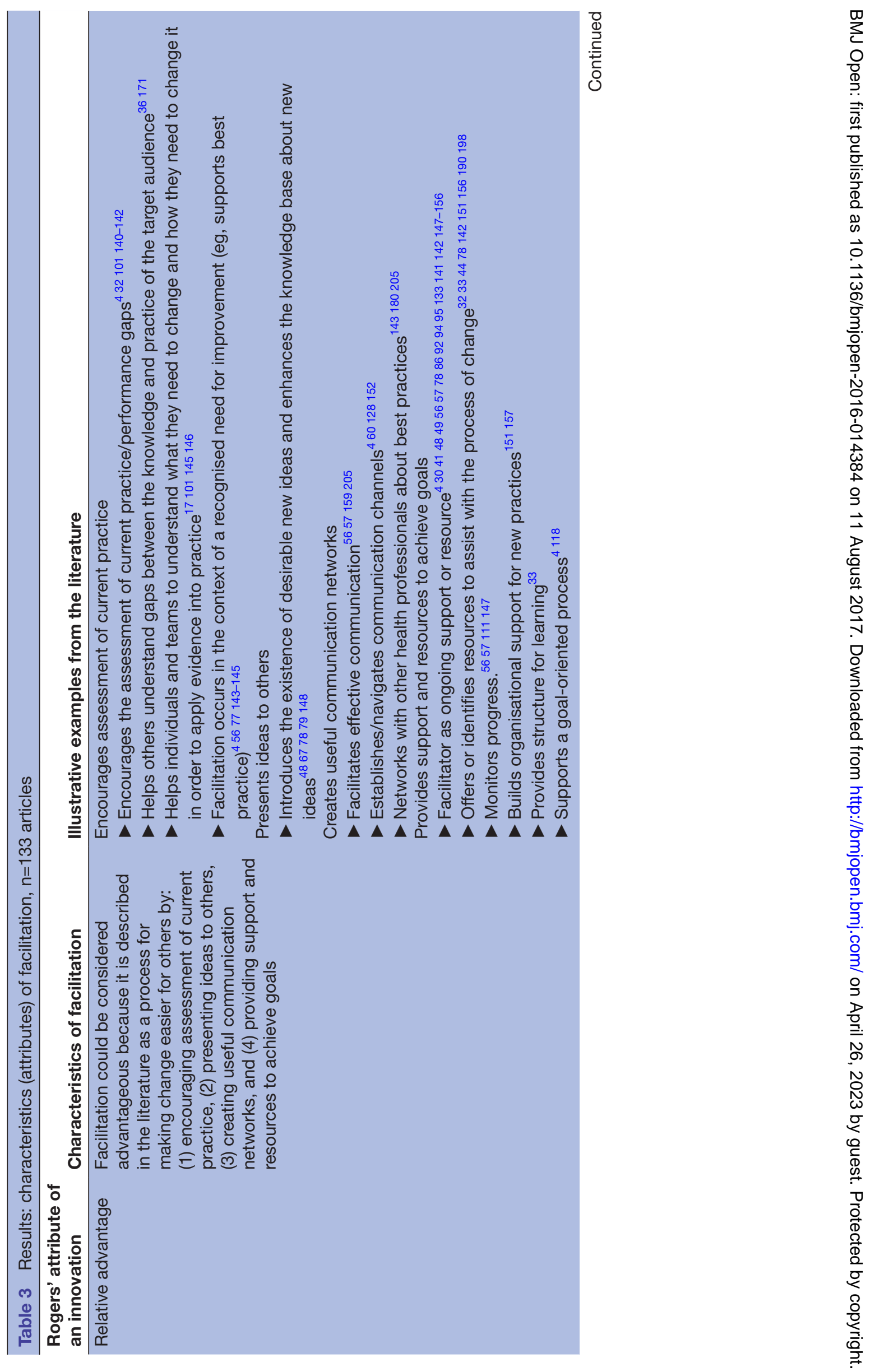




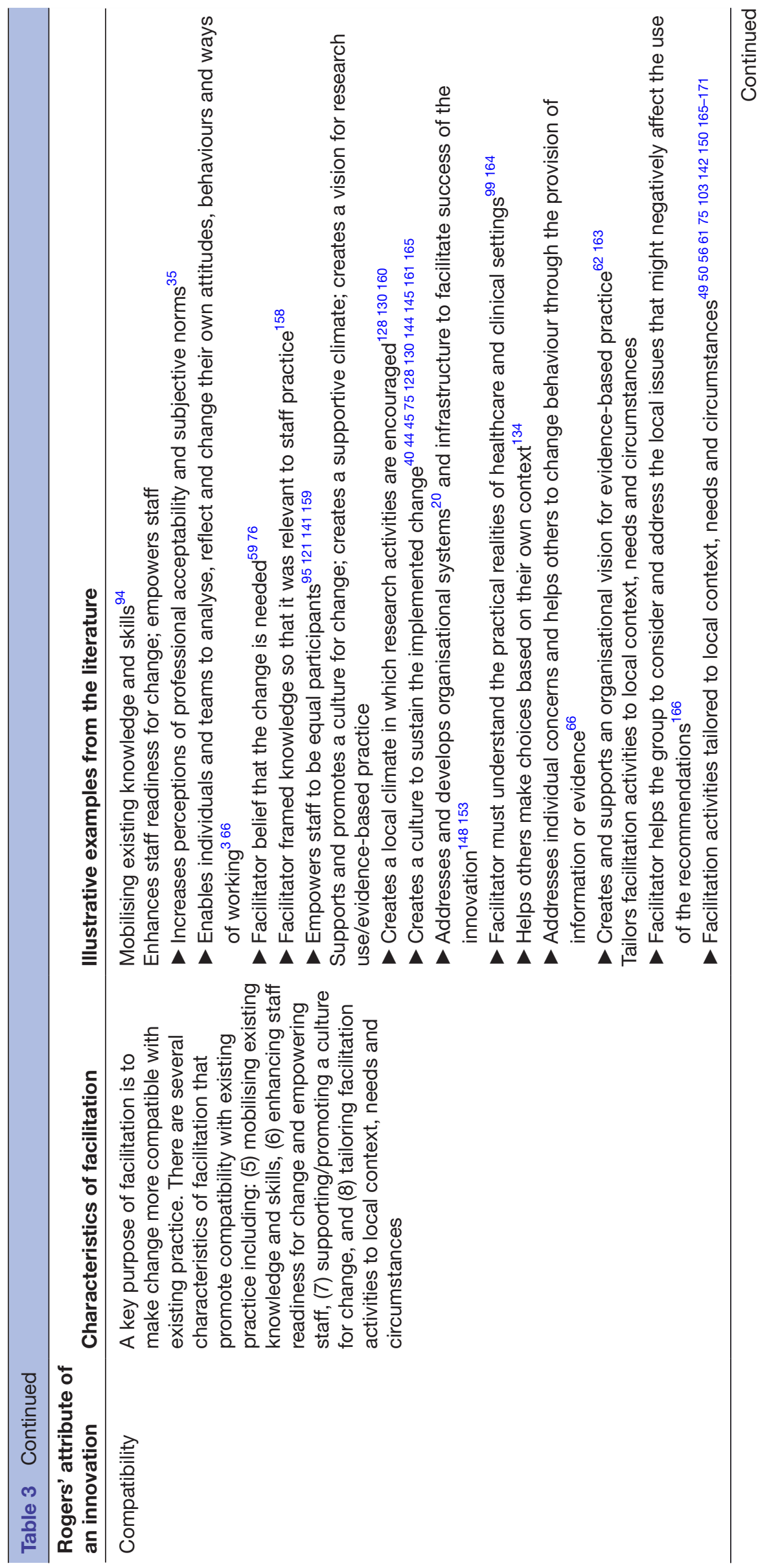




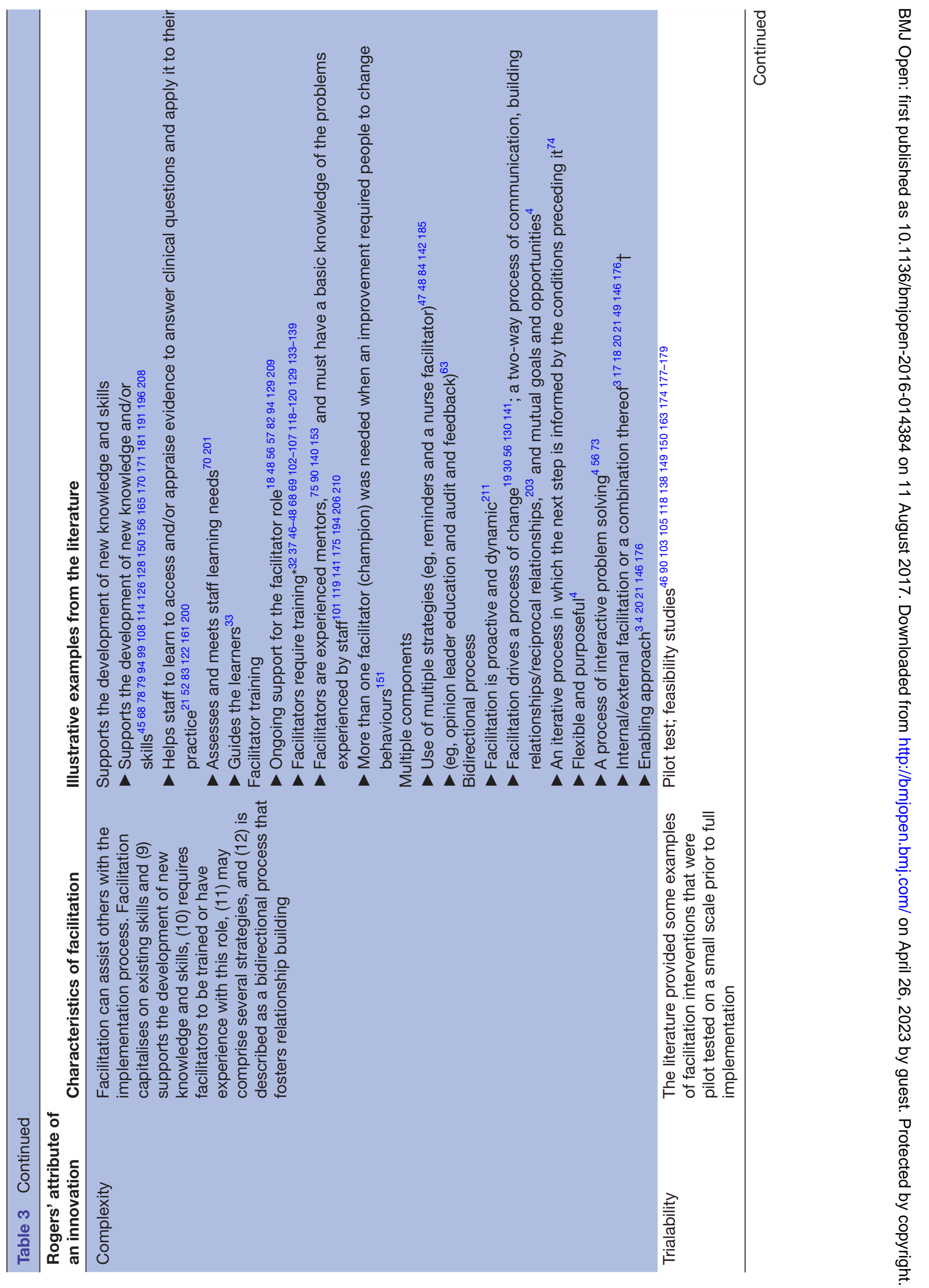




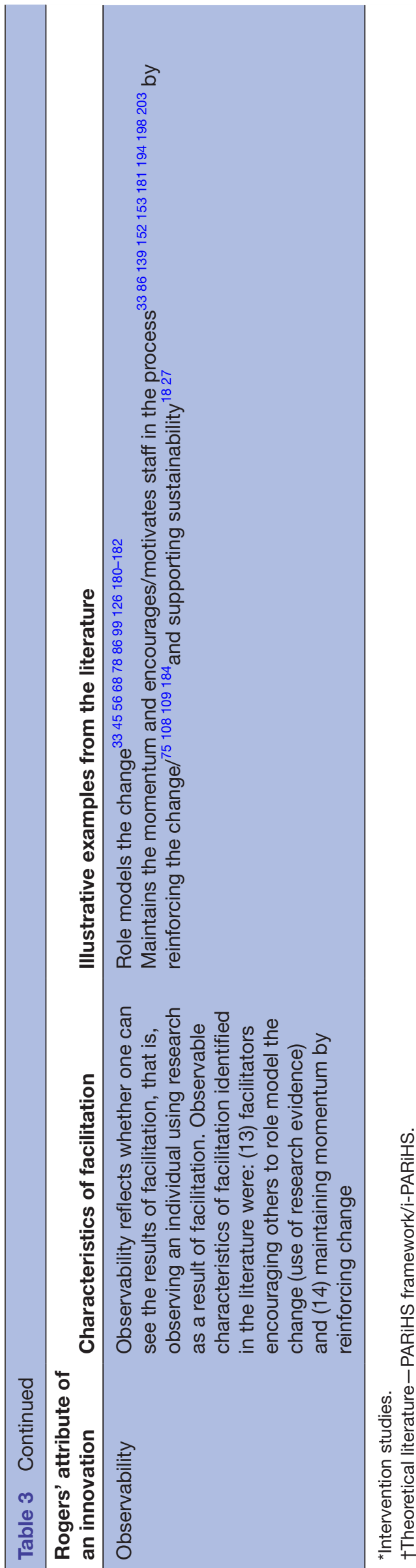

identified in previous reviews. ${ }^{19} 2024$ For each role, we provide a definition, key features, training requirements, and key personal attributes and skills (table 2). As each facilitator role included change agent activities, ${ }^{24}$ we did not include change agent as a separate role.

Stakeholder feedback on the identified facilitator roles was positive and validated our findings. Stakeholders indicated that roles and characteristics were understandable and meaningful. They commented that understanding the key role and skills of each type of facilitator, and whether training was required, was useful in hiring processes.

A key goal and responsibility in all nine facilitator roles is to drive and motivate a practice change and to act as a resource for making the change. Overall, facilitator roles included attributes and skills such as credibility, trustworthiness, expertise, enthusiasm and good problem-solving and networking skills. Opinion leaders, coaches, champions, research facilitators and clinical/ practice facilitators all work internally (locally) within the organisation. Two main features of opinion leaders as facilitators are: they are peer nominated ${ }^{42} 60-68$ and they are informal leaders who are influential because they are knowledgeable and experienced. ${ }^{42}$ 63 69-71

Opinion leadership stems from medical literature ${ }^{71}$ and is based on diffusion of innovation ${ }^{15}$ and social influence theory. ${ }^{242}$ Opinion leaders have wide interpersonal communication networks ${ }^{6061}$ and therefore have a key role in assisting others to recognise the need for improvement and communicating information about innovation within professional networks. ${ }^{42}$ Coaching has been used in the business/management literature as an approach to training, ${ }^{73}$ and more recently has been theoretically positioned in the context of EBP as a relational approach. ${ }^{74} \mathrm{~A}$ coach assists others with making a change particularly in guiding their learning during implementation using motivation, encouragement and positive reinforcement. ${ }^{756} \mathrm{~A}$ champion, whose role is also based on diffusion of innovation ${ }^{40}$ and social influence theory, ${ }^{24}$ is a local visionary who uses expert knowledge and vision to persuade others to adopt an innovation ${ }^{24374877-79}$; and help others to see the advantages of making a practice change and mentor them through the process.

Research facilitators, clinical/practice facilitators, outreach facilitators, linking agents, knowledge brokers and external-internal facilitators were considered more formally appointed roles, and the majority of these facilitators were typically trained for their role. Research facilitators, described in the context of EBP, have expertise (research, clinical background) to support staff to strengthen their research skills, knowledge and participation in research in a clinical setting. ${ }^{39-83}$ A clinical/ practice facilitator, also described in the context of EBP (eg, guideline implementation), provides ongoing education and support through the implementation process $^{30} 324551$ 84-101 (though some were external). Facilitator roles considered external to the organisation included outreach facilitators, linking agents and 
Table 4 Results: Definitions of facilitation

\begin{tabular}{|c|c|c|}
\hline First author/year & Definition of facilitation & $\begin{array}{l}\text { Number of } \\
\text { citations }\end{array}$ \\
\hline $\begin{array}{l}\text { PARiHS framework } \\
\text { Kitson }(2008,1998)^{317}\end{array}$ & $\begin{array}{l}\text { Facilitation is 'a technique by which one person makes things easier for others' ( } p \text { 152). } \\
\text { 'The term describes the type of support required to help people change their attitudes, } \\
\text { habits, skills, ways of thinking, and working.' ( } p \text { 152) }\end{array}$ & $n=19$ \\
\hline Harvey $(2002)^{20}$ & $\begin{array}{l}\text { Facilitation refers to 'the process of enabling (making easier) the implementation of } \\
\text { evidence into practice' ( } p 579) \text {. 'Facilitation is achieved by an individual carrying out a } \\
\text { specific role (a facilitator), which aims to help others.' ( } p 579)\end{array}$ & \\
\hline Schwartz $(2002)^{212}$ & $\begin{array}{l}\text { 'A process of enabling individuals, groups, or teams to work effectively together to } \\
\text { achieve a common goal.' (cited in ref } 18, \text { p 296) }\end{array}$ & $n=1$ \\
\hline Ferguson $(2004)^{29}$ & $\begin{array}{l}\text { 'Facilitation involves helping others to identify questions of practice; providing support } \\
\text { to enable others to meet specific goals, including research use; attending to the process } \\
\text { of achieving those goals; and knowing the system in which change is proposed and } \\
\text { implemented.' (p 325) }\end{array}$ & $\mathrm{n}=0$ \\
\hline Stetler $(2006)^{4}$ & $\begin{array}{l}\text { 'Facilitation is a deliberate and valued process of interactive problem solving and } \\
\text { support that occurs in the context of a recognized need for improvement and a } \\
\text { supportive interpersonal relationship. Facilitation is primarily a distinct role with a } \\
\text { number of potentially crucial behaviors and activities.' (Abstract paragraph 4) }\end{array}$ & $n=4$ \\
\hline Petrova $(2010)^{30}$ & $\begin{array}{l}\text { 'Facilitation is the process of providing support to individuals or groups to achieve } \\
\text { beneficial change' ( } \mathrm{p} 38 \text { ). It has been described as 'the provision of opportunity, } \\
\text { resources, encouragement and support for the group to succeed in achieving its own } \\
\text { objectives and to do this through enabling the group to take control and responsibility } \\
\text { for the way they proceed.' ( } p 38 \text { ) }\end{array}$ & $\mathrm{n}=1$ \\
\hline Dogherty $(2010)^{19}$ & $\begin{array}{l}\text { 'Facilitation is viewed as both an individual role as well as a process involving } \\
\text { individuals and groups.' ( } p \text { 86) }\end{array}$ & $n=3$ \\
\hline
\end{tabular}

knowledge brokers (the latter two being boundary spanner roles). An outreach facilitator assists healthcare providers (eg, those in primary care practices) through a formal implementation process (eg, using educational outreach visits/academic detailing/quality improvement). ${ }^{69102-120}$ A clinical/practice facilitator or outreach facilitator role may be useful when staff are required to learn new skills for research implementation. The linking agent role is based on the concept of spanning the boundary between research and practice to bring about change. $^{24} 29$ 121-123 The knowledge broker role is based on the concepts of linkage and exchange (eg, establishing communication channels), ${ }^{43} 116$ 124-126 knowledge management and capacity building (eg, builds relationships between two communities, typically policymakers and researchers). ${ }^{127} 128$ Recent studies focus on using external-internal facilitators based on the PARiHS framework-described as external facilitators (eg, research team members) supporting internal (local) facilitators to assist healthcare providers with implementing a practice change. $^{49} 5657129130$

Training requirements were a key distinguishing feature of the facilitator roles. External facilitators tended to be formally trained for their role but internal facilitators may or may not have received training.
Only the opinion leader role was described as informal (with no training required). ${ }^{42} \quad 60-67131132$ Of the 63 intervention studies, 24 identified training facilitators. $^{323746-486869102-107118-120129133-139}$ Seventeen of these 24 studies described training components, with nine studies including length of training, ranging from 4 hours, ${ }^{107}$ 40 hours, ${ }^{118} 1-3$ days ${ }^{68} 102137-139$ to 6-7.5 months. ${ }^{32} 106$ Training components typically included course work (theoretical knowledge), ${ }^{3747102119120}$ or both course work and practical experience (skills training)..$^{22} 48106107118$ 137-139

In a recent article describing the i-PARiHS framework, Kitson and Harvey ${ }^{18}$ outline facilitator activities, and further identify three distinct facilitator roles: novice, experienced and expert facilitator. For example, the novice facilitator is skilled at clarifying tasks, and identifying key stakeholders; experienced facilitators support novices, assess system-wide activities and contextual issues, and develop skills in sustaining change; expert facilitators are positioned at a strategic level to provide project coordination and leadership for the initiative, and includes engaging stakeholders and political negotiation skills. ${ }^{18}$

\section{Characteristics of facilitation}

Within our sample of 195 articles, there were 133 articles from which we identified 15 characteristics of facilitation 
associated with research use by healthcare providers, and mapped these onto Rogers' five attributes of innovation: (1) relative advantage (four characteristics), (2) compatibility (four characteristics), (3) complexity (four characteristics), (4) trialability (one characteristic) and (5) observability (two characteristics) ${ }^{15}$ Each of these attributes is described next and shown in table 3.

\section{Relative advantage}

Relative advantage is one of the strongest predictors of successful implementation and an innovation's adoption rate, and was the most frequently cited attribute of facilitation in our review. ${ }^{15}$ The relative advantage or benefit of facilitation is that it involves a process for making change easier for others. We found four characteristics of facilitation considered advantageous to those involved in implementing research into practice: (1) encourages assessment of current practice; (2) presents ideas to others; (3) creates useful communication networks; and (4) provides support and resources to achieve goals. A facilitator can help healthcare professionals to identify gaps between knowledge and practice, ${ }^{4} 3236101127$ 140-142 and to acknowledge the need for improvement. ${ }^{4567143-145}$ Facilitators can assist others to understand the relative advantage of making a change, ${ }^{17} 101145146$ as well as the benefit of facilitation as an implementation innovation itself. A facilitator provides continuing support and identifies resources to help with the process, and monitors

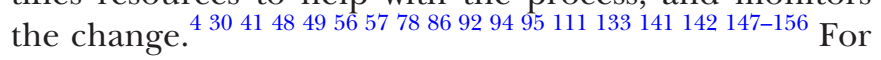
example, a facilitator builds organisational support for new practices ${ }^{151} 157$ and provides structure for learning. ${ }^{33}$

\section{Compatibility}

A key purpose of facilitation is to make change more compatible with existing practices. Several characteristics of facilitation promote compatibility of the change with existing practice including: mobilising existing knowledge and skills ${ }^{94}$; enhancing staff readiness to change and empowering staff 35667695121141158159 ; supporting a culture for change e20 2740444562667599128134144145148153 160-165; and tailoring facilitation activities to local context (eg, social, cultural). ${ }^{49} 50566175103142150166-171$ For example, a facilitator understands the climate and practical realities of the organisation, ${ }^{27} 99128160164$ and frames knowledge so that it is relevant to staff practice. ${ }^{158}$

\section{Complexity}

Facilitation supports the development of new knowledge and skills, requires facilitators to be trained or have experience with this role, may have multiple components, and is described as a bidirectional process that fosters relationship building. A complex intervention typically contains several interacting components. ${ }^{172}$ Most intervention studies in this review described a single intervention but interventions tended to be multifaceted, with several components or strategies typically delivered by a facilitator (eg, audit and feedback, consensus building). ${ }^{103}$ Eleven studies used multiple interventions (ie, more than one intervention arm), ${ }^{4763686984125129142173-175}$ for example, reminders and a nurse facilitator, ${ }^{84}$ and opinion leader education and audit and feedback. ${ }^{63}$ However, facilitation as an innovation need not be complex. Facilitation is an enabling approach ${ }^{342021} 146176$ that can help reduce the (perceived or actual) complexity of a multifaceted intervention. Facilitation involves building trust and fostering mutual opportunities. ${ }^{40} 74$ Facilitators are experienced or are trained for their role to support others with implementation. The frequency and duration (dose) of facilitation varies; for example, some studies included daily facilitation for 3 months ${ }^{90}$ monthly for 12 months, ${ }^{104}$ and on average 25 visits per site lasting 1 hour for 18 months. ${ }^{105}$

\section{Trialability}

The ability for potential adopters to test an intervention can enhance its adoption. ${ }^{15}$ We located examples of researchers who pilot tested a facilitation intervention (or its components) prior to full-scale evaluations. $^{46} 90103105118138149150163174177-179$ For example, in one study six nurses were trained for their facilitator role and gained experience conducting outreach visits in pilot general practices. ${ }^{105}$

\section{Observability}

Observability is seeing the results of an innovation, in our case being able to ascertain that individuals use research as a result of facilitation. ${ }^{15}$ Two characteristics of facilitation that reflected observability were facilitators encouraging others to role model the change $33458699126180-182$ and reinforcing the change (research use) ${ }^{75} 108109183184$ and supporting sustainability. ${ }^{18} 27$ Some examples of role modelling included sharing examples of good practice ${ }^{68}$ and providing opportunities for formal shadowing. ${ }^{126} \mathrm{An}$ example of reinforcing the change was a follow-up visit by a nurse facilitator to reinforce guideline implementation. ${ }^{109}$

\section{Facilitation process}

Although facilitation is identified in the literature as a process of enabling implementation of evidence into practice, ${ }^{19}{ }^{20}$ few studies identified the actual process. Dogherty and colleagues outlined four stages of facilitation that include activities to facilitate research use in nursing: (1) planning for change, (2) leading and managing change, (3) monitoring progress and ongoing implementation, and (4) evaluating change. ${ }^{19} 2756$ Elnitsky and colleagues ${ }^{141}$ described an internal facilitation process (within the organisation): learning the role of facilitator, assessing the culture, facilitating external programmes, negotiating and getting buy-in. They mapped this process to Dogherty and colleagues' facilitation taxonomy (above) and subdomains of the PARiHS framework. ${ }^{155}$ Others have described facilitation as an interactive problem-solving process requiring supportive interpersonal relationships. ${ }^{4}$ Dogherty and colleagues ${ }^{185}$ described key factors to successful facilitation of EBP such 
as development of strategic partnerships, use of multiple strategies to effect change, and facilitator characteristics and approach (eg, leadership and team building skills). Barriers influencing the facilitation process were largely contextual constraints such as lack of engagement and resources and team functioning.

\section{DISCUSSION}

Our review suggests that facilitation has become an important aspect of implementing research into practice, and has potential to be an effective innovation. Our literature synthesis advances previous reviews on facilitation by broadening our understanding of the roles of facilitators and the characteristics of facilitation. ${ }^{19} 2024$ Our first research question addressed the key facilitator roles identified in the literature. We identified nine types of facilitator roles, the majority of which are formal appointed roles. Facilitators share a common goal of implementing an EBP change, and some roles share theoretical underpinnings-opinion leaders and champion roles are based on diffusion of innovation and social influence theory, and a linking agent and knowledge broker act as intermediaries/boundary spanners to bridge gaps. However, we have also highlighted some notable differences in these roles. Clearly, many facilitator roles are being used in healthcare systems. Our findings shed light on the variety, complexity and need for these roles. Policymakers can use these findings to design role statements and processes to impact outcomes for care providers and patients. Knowing the various types of facilitator roles can assist administrators and managers to implement a facilitator role that best supports change activities in their setting. For example, an outreach facilitator could be potentially useful in settings such as outpost nursing and home care. Boundary spanner facilitator roles may be most useful to bridge practitioners with internal and external stakeholders involved in planned change. The importance of external facilitators supporting internal facilitators in creating organisational facilitation capacity is highlighted in the literature. ${ }^{27} 41495657129$ Building internal facilitation capacity may create sustainable infrastructures to support implementation activities designed for improving patient safety and quality of care delivery. Further research should be undertaken on external-internal facilitator roles as they may foster a more integrated approach to facilitating the use of research into practice.

Our second research question addressed the characteristics of facilitation that contribute to research use by healthcare professionals. Characteristics of facilitation are important because they identify those features that may potentially lead to greater success in implementing change. In the KT literature, the knowledge itself is typically considered the innovation. Studies have shown that facilitation itself should be operationalised as an innovation or tool used to influence implementation of other innovations (eg, guideline implementation via facilitation). ${ }^{32} 4651636975103105107109136$ Using Rogers' framework enabled us to highlight characteristics of facilitation that may influence its adoption as an innovation. ${ }^{15}$ Relative advantage was the most frequently cited attribute of facilitation in our review. Rogers' attributes of an innovation ${ }^{15}$ covered all of the results that we found and therefore it is confirmed to be a comprehensive model to describe characteristics of an innovation.

Further research could examine whether facilitation strategies with Rogers' innovation attributes lead to successful implementation. For example, facilitation that is tailored to local context and offers ongoing support may be better received than a complex intervention. According to Greenhalgh et al, Rogers' concept of reinvention (innovation adaptability) can be considered another innovation attribute that could lead to innovations being adopted more readily. ${ }^{156}$ Though we did not include the concept reinvention in our data analysis, three articles from our review described reinvention of the innovation as an important quality to enhance adoption. ${ }^{41148183}$ For example, Miller et alsuggested designing a KT intervention with reinvention in mind, which involves knowing the attributes of the intervention that must be maintained for effectiveness ${ }^{183}$; this is important for adoption and sustainability of an innovation. ${ }^{41}$ Facilitators can assist with reinvention during implementation to individualise the innovation to better meet adopters' needs. ${ }^{148}$ Reinvention as an attribute of an innovation could be explored in future reviews. Understanding these innovation attributes can lay the groundwork for well-designed and well-evaluated facilitation interventions to improve practice in healthcare delivery. However, we noted key gaps in the literature on the characteristics of facilitation. First, the process of facilitation remains unclear and largely implicit, which challenges descriptions of facilitation interventions for future study. Second, few studies were conducted in home care and long-term care settings, which is important to address as Canada and other countries are experiencing a shift in population demographics towards an ageing generation.

Two main limitations of our review, which may introduce the potential for publication bias, are that we did not include grey literature, nor did we conduct a quality appraisal of included studies as this is not part of a scoping study undertaking $^{28} 187$ nor the purpose of our review. The scoping review enabled us to synthesise a breadth of literature that characterises the quantity, nature and extent of research evidence on facilitation ${ }^{187}$ and the roles undertaken to facilitate the uptake of evidence. Our search was further restricted to the English language. However, we tracked non-English language studies and could have included four of them. Our review was focused on research use specifically among healthcare professionals, which has a considerable body of literature that theorises, conceptualises and operationalises facilitation. While this diversity creates some inconsistencies in naming facilitator roles, it has a notable strength; the diversity of the disciplines that describe facilitator roles and characteristics of facilitation from various theoretical perspectives helps us to better understand facilitation. 
High-quality rigorous studies are needed on facilitation to distinguish those characteristics or components that have greatest impact and effectiveness. While we did not assess rigour in this scoping review, others have noted a lack of rigorous studies evaluating facilitation. ${ }^{27}$ Our team is currently completing a systematic review to examine the effectiveness of facilitation as an implementation innovation in healthcare. Such work could also help to shed light on the process of facilitation, what facilitator role is best used and when, and what types of training are most effective for facilitators.

\section{CONCLUSION}

This scoping review highlights a diverse and broad literature on the concept of facilitation that can expand our current thinking about facilitation as an innovation and its potential to support an integrated, collaborative approach to improving healthcare delivery. Implementing research into practice to improve patient care is complex and requires dedicated facilitators to support the change process. This scoping review advances the field of KT science by contributing to the evidence base needed to develop measures of facilitation and to design and test facilitation interventions for successful research use.

Acknowledgements We gratefully acknowledge stakeholders who reviewed the summary table of facilitator roles. We thank Ms Tara MacGregor (research assistant) for her contribution in data screening and extraction and Ms Thane Chambers (Research Librarian, Faculty of Nursing, University of Alberta) for designing and conducting the search strategy. CAE holds a CIHR Canada Research Chair in Knowledge Translation (Tier 1) (2005-2018). GGC holds a University of Alberta Centennial Professorship (2013-2020).

Collaborators Caroline Clark: Associate Executive Director, Brain Care Centre, Edmonton, $\mathrm{AB}$.

Contributors CAE and LAC conceived of the study and secured funding for the study. LAC and FT screened search results for inclusion and extracted data from included articles. CAE conceived of the data analysis framework. LAC, GGC, FT and JPM participated in data analysis and synthesis. LAC and FT drafted the manuscript. All authors provided critical comments on the manuscript. CC (contributor) assisted with the stakeholder consultation.

Funding This work was supported by the Canadian Institutes of Health Research (ClHR) Knowledge Translation Synthesis Program, grant number: KRS 102076.

Competing interests None declared.

Provenance and peer review Not commissioned; externally peer reviewed. Data sharing statement № additional data is available.

Open Access This is an Open Access article distributed in accordance with the Creative Commons Attribution Non Commercial (CC BY-NC 4.0) license, which permits others to distribute, remix, adapt, build upon this work non-commercially, and license their derivative works on different terms, provided the original work is properly cited and the use is non-commercial. See: http://creativecommons.org/ licenses/by-nc/4.0/

(C) Article author(s) (or their employer(s) unless otherwise stated in the text of the article) 2017. All rights reserved. No commercial use is permitted unless otherwise expressly granted.

\section{REFERENCES}

1. Grol R, Grimshaw J. From best evidence to best practice: effective implementation of change in patients' care. The Lancet 2003;362:1225-30.
2. Harrison MB, Legare F, Graham ID, et al. Adapting clinical practice guidelines to local context and assessing barriers to their use. Can Med Assoc J 2010;182:E78-E84.

3. Kitson AL, Rycroft-Malone J, Harvey G, et al. Evaluating the successful implementation of evidence into practice using the PARiHS framework: theoretical and practical challenges. Implement Sci 2008;3:1.

4. Stetler CB, Legro MW, Rycroft-Malone J, et al. Role of "external facilitation" in implementation of research findings: a qualitative evaluation of facilitation experiences in the Veterans Health Administration. Implement Sci 2006;1:23.

5. Urquhart R, Porter GA, Sargeant J, et al. Multi-level factors influence the implementation and use of complex innovations in Cancer care: a multiple case study of synoptic reporting. Implement Sci 2014;9.

6. Estabrooks CA, Floyd JA, Scott-Findlay S, et al. Individual determinants of research utilization: a systematic review. J Adv Nurs 2003;43:506-20.

7. Squires JE, Estabrooks C, Gustavsson P, et al. Individual determinants of research use by nurses: a systematic review update. Implement Sci 2011;5.

8. Boström A-M, Wallin L, Nordström G. Evidence-based practice and determinants of research use in elderly care in Sweden. $J$ Eval Clin Pract 2007:13:665-73.

9. Squires JE, Estabrooks CA, Scott SD, et al. The influence of organizational context on the use of research by nurses in Canadian pediatric hospitals. BMC Health Serv Res 2013;13:351.

10. Cummings GG, Estabrooks CA, Midodzi WK, et al. Influence of organizational characteristics and context on Research utilization. Nurs Res 2007;56:S24-S39.

11. Estabrooks C, Midodzi W, Cummings G, et al. Predicting research use in nursing organizations: a multi-level analysis. Nurs Res 2007;56:S7-23.

12. Estabrooks CA, Scott $\mathrm{S}$, Squires JE, et al. Patterns of research utilization on patient care units. Implement Sci 2008;3:31.

13. Cammer A, Morgan D, Stewart N, et al. The Hidden Complexity of Long-Term Care: how Context mediates Knowledge translation and use of best Practices. Gerontologist 2014;54:1013-23.

14. Urquhart R, Porter GA, Grunfeld E, et al. Exploring the interpersonal-, organization-, and system-level factors that influence the implementation and use of an innovation-synoptic reporting-in Cancer care. Implement Sci 2012;7:12.

15. Rogers EM. Diffusion of innovations. 5th ed. New York: Free Press, 2003.

16. Estabrooks CA, Thompson DS, Lovely JJE, et al. A guide to knowledge translation theory. $J$ Contin Educ Health Prof 2006;26:25-36.

17. Kitson A, Harvey G, McCormack B. Enabling the implementation of evidence based practice: a conceptual framework. Quality and Safety in Health Care 1998;7:149-58.

18. Kitson AL, Harvey G. Methods to succeed in effective knowledge translation in clinical practice. Journal of Nursing Scholarship 2016;48:294-302.

19. Dogherty E, Harrison M, Graham I. Facilitation as a role and process in achieving evidence based practice in nursing: a focused review of concept and meaning. Worldviews Evid Based Nurs 2010;7:76-89.

20. Harvey G, Loftus-Hills A, Rycroft-Malone J, et al. Getting evidence into practice: the role and function of facilitation. $J$ Adv Nurs 2002;37:577-88.

21. Rycroft-Malone J, Harvey G, Kitson A, et al. Getting evidence into practice: ingredients for change. Nurs Stand 2002;16:38-43.

22. Burrows DE. Facilitation: a concept analysis. J Adv Nurs 1997;25:396-404.

23. Berta W, Cranley L, Dearing JW, et al. Why (we think) facilitation works: insights from organizational learning theory. Implement Sci 2015;10:141.

24. Thompson GN, Estabrooks CA, Degner LF. Clarifying the concepts in knowledge transfer: a literature review. J Adv Nurs 2006;53:691-701.

25. Nagykaldi Z, Mold JW, Aspy CB. Practice facilitators: a review of the literature. Fam Med 2005;37:581-8.

26. Baskerville NB, Liddy C, Hogg W. Systematic review and MetaAnalysis of Practice Facilitation within primary care settings. The Annals of Family Medicine 2012;10:63-74.

27. Dogherty EJ, Harrison M, Graham I, et al. Examining the use of facilitation within guideline dissemination and implementation studies in nursing. Int J Evid Based Healthc 2014;12:105-27.

28. Arksey H, O'Malley L. Scoping studies: towards a methodological framework. Int J Soc Res Methodol 2005;8:19-32. 
29. Ferguson L, Milner M, Snelgrove-Clark E. The role of intermediaries: getting evidence into practice. J Wound Ostomy Continence Nurs 2004;31:325-7

30. Petrova M, Dale J, Munday D, et al. The role and impact of facilitators in primary care: findings from the implementation of the Gold Standards Framework for palliative care. Fam Pract 2010;27:38-47.

31. Dogherty EJ, Harrison MB, Graham ID. Facilitation as a role and process in achieving evidence-based practice in nursing: a focused review of concept and meaning. Worldviews Evid Based Nurs 2010;7:76-89.

32. Bashir K, Blizard B, Bosanquet A, et al. The evaluation of a mental health facilitator in general practice: effects on recognition, management, and outcome of mental illness. Br J Gen Pract 2000;50:626-9.

33. Lekalakala-Mokgele E, Du Rand PP. A model for facilitation in nursing education. Curationis 2005;28:22-9.

34. Lewin K. Field theory in social science. New York: Harper \& Row, 1951.

35. Bloomfield HE, et al. A trial of education, prompts, and opinion leaders to improve prescription of lipid modifying therapy by primary care physicians for patients with ischemic heart disease. Quality and Safety in Health Care 2005;14:258-63.

36. Borbas C, Morris N, McLaughlin B, et al. The role of clinical opinion leaders in guideline implementation and quality improvement. Chest 2000;118:24S-32.

37. Campbell J. The effect of nurse Champions on Compliance with keystone Intensive Care Unit Sepsis-Screening Protocol. Crit Care Nurs Q 2008;31:251-69.

38. Doran DM, Sidani S. Outcomes-Focused knowledge translation: a framework for Knowledge translation and patient outcomes improvement. Worldviews Evid Based Nurs 2007;4:3-13.

39. Fineout-Overholt E, Melnyk BM, Schultz A. Transforming health care from the inside out: advancing evidence-based practice in the $21 \mathrm{st}$ century. J Prof Nurs 2005;21:335-44.

40. Kavanagh T, Watt-Watson J, Stevens B. An examination of the factors enabling the successful implementation of Evidence-Based acute pain Practices into Pediatric Nursing. Children's Health Care 2007;36:303-21.

41. McWilliam CL, Kothari A, Ward-Griffin C, et al. Evolving the theory and praxis of knowledge translation through social interaction: a social phenomenological study. Implement Sci 2009;4:26.

42. Young JM, et al. Role for Opinion Leaders in Promoting EvidenceBased Surgery. Arch Surg 2003;138:785-91.

43. Dobbins M, Robeson P, Ciliska D, et al. A description of a knowledge broker role implemented as part of a randomized controlled trial evaluating three knowledge translation strategies. Implement Sci 2009;4:23.

44. Aitken LM, Hackwood B, Crouch S, et al. Creating an environment to implement and sustain evidence based practice: a developmental process. Aust Crit Care 2011;24:244-54.

45. English M, Nzinga J, Mbindyo P, et al. Explaining the effects of a multifaceted intervention to improve inpatient care in rural Kenyan hospitals-interpretation based on retrospective examination of data from participant observation, quantitative and qualitative studies. Implement Sci 2011;6:124

46. Foley KL, Pockey JR, Helme DW, et al. Integrating evidencebased tobacco cessation interventions in free medical clinics: opportunities and challenges. Health Promot Pract 2012;13:687-95.

47. Dickinson WP, Dickinson LM, Nutting PA, et al. Practice Facilitation to improve Diabetes Care in primary care: a Report from the EPIC Randomized clinical trial. The Annals of Family Medicine 2014;12:8-16.

48. Gerrish K, Laker S, Taylor C, et al. Enhancing the quality of oral nutrition support for hospitalized patients: a mixed methods knowledge translation study (The EQONS study). J Adv Nurs 2016;72:3182-94.

49. Harvey G, Oliver K, Humphreys J, et al. Improving the identification and management of chronic kidney disease in primary care: lessons from a staged improvement collaborative. Int J Qual Health Care 2015;27:10-16.

50. Ellis I, Howard P, Larson A, et al. From Workshop to work Practice: an exploration of Context and Facilitation in the development of Evidence-Based practice. Worldviews Evid Based Nurs 2005;2:84-93

51. Ayieko $\mathrm{P}$, Ntoburi $\mathrm{S}$, Wagai J, et al. A multifaceted intervention to implement guidelines and improve admission Paediatric Care in kenyan District Hospitals: a cluster randomised trial. PLoS Med 2011;8:e1001018.
52. DeBourgh GA. Champions for Evidence-based practice: a critical role for Advanced Practice Nurses. AACN Clin Issues 2001;12:491-508

53. Donabedian A. Explorations in Quality Assessment and Monitoring Vol. 1. the definition of Quality and Approaches to its Assessment. Ann Arbor, MI: Health Administration Press, 1980.

54. Donabedian A. The quality of care. how can it be assessed? JAMA 1988;260:1743-8

55. Graham ID, Logan J, Harrison MB, et al. Lost in knowledge translation: time for a map? J Contin Educ Health Prof 2006;26:13-24.

56. Dogherty EJ, Harrison MB, Baker C, et al. Following a natural experiment of guideline adaptation and early implementation: a mixed-methods study of facilitation. Implement Sci 2012;7:9.

57. Harrison MB, Graham ID, van den Hoek J, et al. Guideline adaptation and implementation planning: a prospective observational study. Implement Sci 2013;8:49.

58. May CR, Mair F, Finch T, et al. Development of a theory of implementation and integration: normalization process Theory. Implement Sci 2009;4:29.

59. Gotlib Conn L, McKenzie M, Pearsall EA, et al. Successful implementation of an enhanced recovery after surgery programme for elective colorectal surgery: a process evaluation of champions' experiences. Implement Sci 2015;10:99.

60. Grimshaw JM, Eccles MP, Greener J, et al. Is the involvement of opinion leaders in the implementation of research findings a feasible strategy? Implement Sci 2006;1:3.

61. Grimshaw JM, Eccles MP, Lavis JN, et al. Knowledge translation of research findings. Implement Sci 2012;7:50.

62. Locock L, Dopson S, Chambers D, et al. Understanding the role of opinion leaders in improving clinical effectiveness. Soc Sci Med 2001:53:745-57.

63. Lomas J, Enkin M, Anderson GM, et al. Opinion leaders vs audit and feedback to implement practice guidelines. delivery after previous cesarean section. JAMA 1991;265:2202-7.

64. Majumdar SR, Tsuyuki RT, McAlister FA. Impact of opinion leaderendorsed evidence summaries on the quality of prescribing for patients with cardiovascular disease: a randomized controlled trial. Am Heart J 2007;153:22.e1-8.

65. Siddiqi K, Newell J, Robinson M. Getting evidence into practice: what works in developing countries? Int J Qual Health Care 2005;17:447-54.

66. Simpson F, Doig GS. The relative effectiveness of practice change interventions in overcoming common barriers to change: a survey of 14 hospitals with experience implementing evidence-based guidelines. J Eval Clin Pract 2007;13:709-15.

67. Waters D, Rychetnik L, Crisp J, et al. Views on evidence from nursing and midwifery opinion leaders. Nurse Educ Today 2009;29:829-34.

68. Rycroft-Malone J, Seers K, Crichton N, et al. A pragmatic cluster randomised trial evaluating three implementation interventions. Implement Sci 2012;7:80.

69. Goldberg HI, Wagner EH, Finn SD, et al. A Randomized Controlled Trial of CQI Teams and Academic Detailing: can they alter compliance with guidelines? Jt Comm J Qual Improv 1998;24:130-42.

70. Pereles L, Lockyer J, Ryan D, et al. The use of the opinion leader in continuing medical education. Med Teach 2003;25:438-41.

71. Wadhwa A, Ford-Jones EL, Lingard L. A qualitative study of interphysician telephone consultations: extending the opinion leader theory. J Contin Educ Health Prof 2005;25:98-104.

72. Zimbano PG MRL. The psychology of attitude, change and social influence. Philadelphia, PA: Temple University Press, 1991.

73. Fielden SL, Davidson MJ, Sutherland VJ. Innovations in coaching and mentoring: implications for nurse leadership development. Health Serv Manage Res 2009;22:92-9.

74. Drake DB. Evidence is a verb: a relational approach to knowledge and mastery in coaching. IJEBCM 2009;7:1-12.

75. Bender BG, Dickinson P, Rankin A, et al. The Colorado Asthma Toolkit Program: a practice coaching intervention from the High Plains Research Network. J Am Board Fam Med 2011;24:240-8.

76. Ervin NE. Clinical coaching: a strategy for enhancing evidencebased nursing practice. Clin Nurse Spec 2005;19:296-301.

77. Ploeg J, Skelly J, Rowan M, et al. The role of Nursing best practice Champions in Diffusing Practice guidelines: a mixed methods study. Worldviews Evid Based Nurs 2010;7:238-51.

78. Hohlfelder B, Kubiak DW, Degrado JR, et al. Implementation of a Prolonged Infusion Guideline for Time-Dependent Antimicrobial Agents at a Tertiary Academic Medical Center. Am J Ther 2016;23:e1768-e1773. 
79. Kaasalainen S, Ploeg J, Donald F, et al. Positioning clinical nurse specialists and nurse practitioners as Change Champions to implement a pain Protocol in Long-Term Care. Pain Management Nursing 2015;16:78-88.

80. Chummun H, Tiran D. Increasing research evidence in practice: a possible role for the consultant nurse. J Nurs Manag 2008;16:327-33.

81. Eaton E, Henderson A, Winch S. Enhancing nurses' capacity to facilitate learning in nursing students: effective dissemination and uptake of best practice guidelines. Int $J$ Nurs Pract 2007;13:316-20.

82. Logan J, Davies B. The staff nurse as research facilitator. Can J Nurs Adm 1995;8:92-110.

83. Plamondon $\mathrm{K}$, Ronquillo $\mathrm{C}$, Axen $\mathrm{L}$, et al. Bridging Research and Practice through the Nursing Research Facilitator Program in British Columbia. Nurs Leadersh 2013;26:32-43.

84. Ansari M, et al. Improving Guideline adherence: a Randomized Trial evaluating strategies to increase -Blocker Use in Heart Failure. Circulation 2003;107:2799-804.

85. Belizan M, Meier A, Althabe F, et al. Facilitators and barriers to adoption of evidence-based perinatal care in latin american hospitals: a qualitative study. Health Educ Res 2007;22:839-53.

86. Byron S, Moriarty D, O'Hara A, O'Hara A. Macmillan nurse facilitators: establishing a palliative resource nurse network in primary care. Int J Palliat Nurs 2007;13:438-44.

87. de Cordova PB, Collins S, Peppard L, et al. Implementing evidencebased nursing with student nurses and clinicians: uniting the strengths. Applied Nursing Research 2008;21:242-5.

88. Elwyn G, Hocking P, Burtonwood A, et al. Learning to plan? A critical fiction about the facilitation of professional and practice development plans in primary care. $J$ Interprof Care 2002;16:349-58.

89. Gibson M, Woodbury MG, Hay K. Changing pain assessment and management practices in residential care settings using the "readiness for change" model. Can Geriatr J 2008;11:94-8.

90. Jarman HJ. Sharing expertise-using clinical nursing rounds to improve UK emergency nursing practice. Australas Emerg Nurs $J$ 2009;12:73-7.

91. Locca JF, Ruggli M, Buchmann M, et al. Development of pharmaceutical care services in nursing homes: practice and research in a Swiss Canton. Pharm World Sci 2009;31:165-73.

92. Lombarts MJ, Klazinga NS, Redekop KK. Measuring the perceived impact of facilitation on implementing recommendations from external assessment: lessons from the Dutch visitatie programme for medical specialists. J Eval Clin Pract 2005;11:587-97.

93. Mellor F, Foley T, Connolly M, et al. Role of a clinical facilitator in introducing an integrated care pathway for the care of the dying. Int $J$ Palliat Nurs 2004;10:497-501.

94. Moriarty D, O'Hara A, Byron S. Macmillan nurse facilitators for palliative care: evaluation of. Int J Palliat Nurs 2007;13:334-43.

95. Robinson J. Improving practice through a system of clinical supervision. Nurs Times 2005;101:30-2.

96. Ruetz JP. Enabling frontline participation to create a quality improvement culture. Healthc Manage Forum 2007;20:53-5.

97. Wallin L, Rudberg A, Gunningberg L. Staff experiences in implementing guidelines for Kangaroo Mother Care-a qualitative study. Int J Nurs Stud 2005;42:61-73.

98. Sipilä R, Ketola E, Tala T, et al. Facilitating as a guidelines implementation tool to target resources for high risk patients - The Helsinki Prevention Programme (HPP). J Interprof Care 2008;22:31-44.

99. Gerrish K, Nolan M, McDonnell A, et al. Factors influencing Advanced Practice nurses' Ability to Promote Evidence-Based Practice among Frontline Nurses. Worldviews Evid Based Nurs 2012;9:30-9.

100. De Luca A, Caprara A, Barbolini M, et al. Continuing medical education and evidence-based clinical pathways. Training emergency health workers in Latium, Italy. Educ Health 2008;21.

101. Purvis T, Moss K, Denisenko S, et al. Implementation of evidencebased stroke care: enablers, barriers, and the role of facilitators. $J$ Multidiscip Healthc 2014;7:389-400.

102. Engels $\mathrm{Y}$, van den Hombergh $\mathrm{P}$, Mokkink $\mathrm{H}$, et al. The effects of a team-based continuous quality improvement intervention on the management of primary care: a randomised controlled trial. $\mathrm{Br} \mathrm{J}$ Gen Pract 2006;56:781-7.

103. Hogg W, Lemelin J, Graham I, et al. Improving prevention in primary care: evaluating the effectiveness of outreach facilitation. Fam Pract 2008;25:40-8.

104. Hogg W, Lemelin J, Moroz I, et al. Improving prevention in primary care: evaluating the sustainability of outreach facilitation. Can Fam Physician 2008;54:712-20.
105. Hulscher ME, van Drenth BB, van der Wouden JC, et al. Changing preventive practice: a controlled trial on the effects of outreach visits to organise prevention of cardiovascular disease. Qual Health Care 1997;6:19-24.

106. Lemelin J, Hogg W, Baskerville N. Evidence to action: a tailored multifaceted approach to changing family physician practice patterns and improving preventive care. CMAJ 2001;164:757-63.

107. Siegel D, Lopez J, Meier J, et al. Academic detailing to improve antihypertensive prescribing patterns. Am J Hypertens 2003;16:508-11.

108. Linnebur SA, Fish DN, Ruscin JM, et al. Impact of a multidisciplinary intervention on antibiotic use for nursing home-acquired pneumonia. Am J Geriatr Pharmacother 2011;9:442-50.

109. Chan D, Patel P, Booth L, et al. A novel approach for implementing evidence-based guidelines in the community: the appropriate choices in dyspepsia project. J Clin Excellence 2001;2:219-23.

110. Davis DA, Taylor-Vaisey A. Translating guidelines into practice. A systematic review of theoretic concepts, practical experience and research evidence in the adoption of clinical practice guidelines. CMAJ 1997;157:408-16.

111. Hak E, Hermens RP, Hoes AW, et al. Effectiveness of a co-ordinated nation-wide programme to improve influenza immunisation rates in the Netherlands. Scand J Prim Health Care 2000;18:237-41.

112. Hogg W, Baskerville N, Nykiforuk C, et al. Improved preventive care in family practices with outreach facilitation: understanding success and failure. J Health Serv Res Policy 2002;7:195-201.

113. Markey P, Schattner P. Promoting evidence-based medicine in general practice-the impact of academic detailing. Fam Pract 2001;18:364-6.

114. Rugh JD, Sever N, Glass BJ, et al. Transferring evidence-based information from dental school to practitioners: a pilot "academic detailing" program involving dental students. J Dent Educ 2011;75:1316-22.

115. Shipman C, Addington-Hall J, Thompson M, et al. Building bridges in palliative care: evaluating a GP facilitator programme. Palliat Med 2003;17:621-7.

116. Soumerai SB. Principles and uses of academic detailing to improve the management of psychiatric disorders. Int J Psychiatry Med 1998;28:81-96.

117. O'Brien M, Rogers S, Jamtvedt G, et al. Educational outreach visits: effects on professional practice and health care outcomes (Review). Cochrane Database Syst Rev 2008;4.

118. Due TD, Thorsen T, Kousgaard MB, et al. The effectiveness of a semi-tailored facilitator-based intervention to optimise chronic care management in general practice: a stepped-wedge randomised controlled trial. BMC Fam Pract 2014;15:65.

119. Mader EM, Fox CH, Epling JW, et al. A practice facilitation and academic detailing intervention can improve Cancer screening rates in primary care safety net clinics. J Am Board Fam Med 2016;29:533-42.

120. Parchman ML, Noel PH, Culler SD, et al. A randomized trial of practice facilitation to improve the delivery of chronic illness care in primary care: initial and sustained effects. Implement Sci 2013;8:93.

121. Wilkinson JE, Nutley SM, Davies HT. An exploration of the roles of nurse managers in evidence-based practice implementation. Worldviews Evid Based Nurs 2011;8:236-46.

122. Maclntosh-Murray A, Choo CW. Information behavior in the context of improving patient safety. J Assoc Inf Sci Technol 2005;56:1332-45.

123. French $B$. Contextual factors influencing research use in nursing. Worldviews Evid Based Nurs 2005;2:172-83.

124. Armstrong R, Waters $\mathrm{E}$, Crockett $\mathrm{B}$, et al. The nature of evidence resources and knowledge translation for health promotion practitioners. Health Promot Int 2007;22:254-60.

125. Dobbins M, Hanna SE, Ciliska D, et al. A randomized controlled trial evaluating the impact of knowledge translation and exchange strategies. Implement Sci 2009;4:61.

126. Gerrish K, McDonnell A, Nolan M, et al. The role of advanced practice nurses in knowledge brokering as a means of promoting evidence-based practice among clinical nurses. J Adv Nurs 2011;67:2004-14.

127. Bornbaum CC, Kornas K, Peirson L, et al. Exploring the function and effectiveness of knowledge brokers as facilitators of knowledge translation in health-related settings: a systematic review and thematic analysis. Implement Sci 2015;10:162.

128. Catallo C. Should nurses be knowledge brokers? competencies and organizational Resources to support the role. Nurs Leadersh 2015;28:24-37.

129. Harvey G, Kitson A, Munn Z. Promoting continence in nursing homes in four european countries: the use of PACES as a 
mechanism for improving the uptake of evidence-based recommendations. Int J Evid Based Healthc 2012;10:388-96.

130. Dogherty EJ, Harrison M, Graham I, et al. Examining the use of facilitation within guideline dissemination and implementation studies in nursing. Int J Evid Based Healthc 2014;12:105-27.

131. Boaz A, Baeza J, Fraser A, et al. Effective implementation of research into practice: an overview of systematic reviews of the health literature. BMC Res Notes 2011;4:212.

132. Flodgren $\mathrm{G}$, Parmelli $\mathrm{E}$, Doumit $\mathrm{G}$, et al. Local opinion leaders: effects on professional practice and health care outcomes. Cochrane Database Syst Rev 2011;8:CD000125.

133. Acolet $\mathrm{D}$, Allen $\mathrm{E}$, Houston $\mathrm{R}$, et al. Improvement in neonatal intensive care unit care: a cluster randomised controlled trial of active dissemination of information. Arch Dis Child Fetal Neonatal Ed 2011;96:F434-F439.

134. Byng $\mathrm{R}$, Jones $\mathrm{R}$, Leese $\mathrm{M}$, et al. Exploratory cluster randomised controlled trial of shared care development for long-term mental illness. Br J Gen Pract 2004;54:259-66.

135. Ellis JA, McCleary L, Blouin R, et al. Implementing best practice pain management in a pediatric hospital. $J$ Spec Pediatr Nurs 2007;12:264-77.

136. Friedman L, Engelking C, Wickham R, et al. The EDUCATE Study: a continuing education exemplar for Clinical Practice Guideline Implementation. Clin J Oncol Nurs 2009;13:219-30.

137. Holtrop JS, Baumann J, Arnold AK, et al. Nurses as practice change facilitators for healthy behaviors. J Nurs Care Qual 2008;23:123-31.

138. Minnick A, Catrambone CD, Halstead L, et al. A nurse coach quality improvement intervention: feasibility and treatment fidelity. West $J$ Nurs Res 2008;30:690-703.

139. Vaughan C, Reddy P, Dunbar J. From rural beginnings to statewide roll-out: evaluation of facilitator training for a groupbased diabetes prevention program. Aust J Rural Health 2010;18:59-65.

140. Bayley MT, Hurdowar A, Richards CL, et al. Barriers to implementation of stroke rehabilitation evidence: findings from a multi-site pilot project. Disabil Rehabil 2012;34:1633-8.

141. Elnitsky CA, Powell-Cope G, Besterman-Dahan KL, et al. Implementation of Safe Patient Handling in the U.S. Veterans Health System: A Qualitative Study of Internal Facilitators' Perceptions. Worldviews Evid Based Nurs 2015;12:208-16.

142. Eskicioglu C, Pearsall E, Victor JC, et al. A multifaceted knowledge translation strategy can increase compliance with guideline recommendations for mechanical bowel preparation. $J$ Gastrointest Surg 2015;19:39-45

143. Frantsve-Hawley J, Meyer DM. The evidence-based dentistry champions: a grassroots approach to the implementation of EBD. $J$ Evid Based Dent Pract 2008;8:64-9.

144. Harvey G, Fitzgerald L, Fielden S, et al. The NIHR Collaborations for Leadership in Applied Health Research and Care (CLAHRC) for Greater Manchester: combining empirical, theoretical and experiential evidence to design and evaluate a large-scale implementation strategy. Implement Sci 2011;6:96.

145. Liddy C, Laferriere D, Baskerville B, et al. An overview of Practice Facilitation Programs in Canada: current perspectives and future directions. Healthcare Policy | Politiques de Santé 2013;8:58-68.

146. Rycroft-Malone J, Kitson A, Harvey G, et al. Ingredients for change: revisiting a conceptual framework. Qual Saf Health Care 2002;11:174-80.

147. Olson CA, Tooman TR, Alvarado CJ. Knowledge systems, health care teams, and clinical practice: a study of successful change. Adv Health Sci Educ Theory Pract 2010;15:491-516.

148. Shirey MR. Evidence-based practice: how nurse leaders can facilitate innovation. Nurs Adm Q 2006;30:252-65.

149. Wiechula R, Kitson A, Marcoionni D, et al. Improving the fundamentals of care for older people in the acute hospital setting: facilitating practice improvement using a knowledge translation toolkit. Int J Evid Based Healthc 2009;7:283-95.

150. Pannucci CJ, Jaber RM, Zumsteg JM, et al. Changing practice: implementation of a venous thromboembolism prophylaxis protocol at an academic medical center. Plast Reconstr Surg 2011;128:1085-92.

151. Damschroder LJ, Banaszak-Holl J, Kowalski CP, et al. The role of the champion in infection prevention: results from a multisite qualitative study. Qual Saf Health Care 2009;18:434-40.

152. Kelly D, Simpson S, Brown P. An action research project to evaluate the clinical practice facilitator role for junior nurses in an acute hospital setting. J Clin Nurs 2002;11:90-8.

153. Muller A, McCauley K, Harrington P, et al. Evidence-based practice implementation strategy: the central role of the clinical nurse specialist. Nurs Adm Q 2011:35:140-51.
154. Penz KL, Bassendowski SL. Evidence-based nursing in clinical practice: implications for nurse educators. J Contin Educ Nurs 2006;37:250-4

155. Stetler CB, Damschroder LJ, Helfrich CD, et al. A Guide for applying a revised version of the PARIHS framework for implementation. Implement Sci 2011;6:99.

156. García-Elorrio E, Aleman A, Cafferata ML, et al. A multifaceted intervention to increase prophylactic oxytocin use during the third stage of labor and to reduce routine episiotomies in Nicaragua. Int $J$ Gynaecol Obstet 2014;127:31-4.

157. Nagykaldi Z, Mold JW, Robinson A, et al. Practice facilitators and practice-based research networks. J Am Board Fam Med 2006;19:506-10.

158. Janes $\mathrm{N}$, Fox M, Lowe M, et al. Facilitating best practice in aged care: exploring influential factors through critical incident technique. Int J Older People Nurs 2009;4:166-76.

159. Gurzick M, Kesten KS. The impact of clinical nurse specialists on clinical pathways in the application of evidence-based practice. $J$ Prof Nurs 2010;26:42-8.

160. Harrison LL, Kitchens EK. Implementing the research facilitator role. Nurse Educ 1989;14:21-6.

161. Jamerson PA, Vermeersch P. The role of the nurse research facilitator in building research capacity in the clinical setting. $J$ Nurs Adm 2012;42:21-7.

162. King CC, Craig BJ. The role of the dental hygienist as change agent. Probe 1997;31:81-3.

163. Ploeg J, Davies B, Edwards N, et al. Factors influencing bestpractice guideline implementation: lessons learned from administrators, nursing staff, and project leaders. Worldviews Evid Based Nurs 2007;4:210-9.

164. Clarkson JE, Bonetti D. Why be an evidence-based dentistry champion? J Evid Based Dent Pract 2009;9:145-50.

165. Taylor EF, Machta RM, Meyers DS, et al. Enhancing the primary care team to provide redesigned care: the roles of practice facilitators and care managers. Ann Fam Med 2013;11:80-3.

166. Graham ID, Harrison MB, Brouwers M, et al. Facilitating the use of evidence in Practice: evaluating and adapting Clinical Practice guidelines for Local use by Health Care Organizations. Journal of Obstetric, Gynecologic \& Neonatal Nursing 2002;31:599-611.

167. Aberg AC, Lundin-Olsson L, Rosendahl E. Implementation of evidence-based prevention of falls in rehabilitation units: a staff's interactive approach. J Rehabil Med 2009;41:1034-40.

168. Grol R, Grimshaw J. Evidence-based implementation of evidencebased medicine. Jt Comm J Qual Improv 1999;25:503-13.

169. Matthew-Maich N, Ploeg J, Jack S, et al. Leading on the frontlines with passion and persistence: a necessary condition for Breastfeeding best practice guideline uptake. J Clin Nurs 2013;22:1759-70.

170. Ragazzi $\mathrm{H}$, Keller A, Ehrensberger R, et al. Evaluation of a practicebased intervention to improve the management of pediatric asthma. J Urban Health 2011;88(Suppl 1):38-48.

171. Schleifer Taylor J, Verrier MC, Landry MD. What do we Know about Knowledge brokers in Paediatric Rehabilitation? A systematic search and Narrative Summary. Physiother Can 2014:66:143-52.

172. Craig P, Dieppe P, Macintyre S, et al. Developing and evaluating complex interventions: the new Medical Research Council guidance. BMJ 2008;337:a1655-83.

173. Mold JW, Aspy CA, Nagykaldi Z. Implementation of evidencebased preventive services delivery processes in primary care: an Oklahoma Physicians Resource/Research Network (OKPRN) study. J Am Board Fam Med 2008;21:334-44.

174. Pattinson RC, Arsalo I, Bergh AM, et al. Implementation of kangaroo mother care: a randomized trial of two outreach strategies. Acta Paediatr 2005;94:924-7.

175. Tjia J, Field T, Mazor K, et al. Dissemination of Evidence-Based Antipsychotic Prescribing guidelines to Nursing Homes: a Cluster Randomized Trial. J Am Geriatr Soc 2015;63:1289-98.

176. Rycroft-Malone J. The PARIHS framework--a framework for guiding the implementation of evidence-based practice. J Nurs Care Qual 2004:19:297-304

177. Sullivan G, Duan N, Mukherjee S, et al. The role of services researchers in facilitating intervention research. Psychiatr Serv 2005:56:537-42.

178. Edwards A, Rhydderch M, Engels Y, et al. Assessing organisational development in european primary care using a group-based method. Int J Health Care Qual Assur 2010;23:8-21.

179. Fineout-Overholt E, Levin RF, Melnyk BM. Strategies for advancing evidence-based practice in clinical settings. J N Y State Nurses Assoc 2004;35:28-32.

180. Russell-Babin KA. Calling all opinion leaders! Keys to the diffusion of evidence. Nurs Manage 2010;41:8-11. 
181. Buonocore D. Leadership in action: creating a change in practice. AACN Clin Issues 2004;15:170-81.

182. Michael R. Facilitating nursing research: a professional mandate for perioperative nurses. Can Oper Room Nurs J 2007;25:18-22.

183. Miller WR, Sorensen JL, Selzer JA, et al. Disseminating evidencebased practices in substance abuse treatment: a review with suggestions. J Subst Abuse Treat 2006;31:25-39.

184. Ang E, Chow YL. General pain assessment among patients with Cancer in an acute care setting: a best practice implementation project. Int J Evid Based Healthc 2010;8:90-6.

185. Dogherty EJ, Harrison MB, Graham ID, et al. Turning knowledge into action at the point-of-care: the collective experience of nurses facilitating the implementation of evidence-based practice. Worldviews Evid Based Nurs 2013;10:129-39.

186. Greenhalgh T, Robert G, Macfarlane F, et al. Diffusion of innovations in service organizations: systematic review and recommendations. Milbank Q 2004;82:581-629.

187. Grant MJ, Booth A. A typology of reviews: an analysis of 14 review types and associated methodologies. Health Info Libr J 2009;26:91-108.

188. Cronje RJ, Moch SD. Part III. reenvisioning undergraduate nursing students as opinion leaders to diffuse evidence-based practice in clinical settings. J Prof Nurs 2010;26:23-8.

189. Guihan M, Bosshart HT, Nelson A. Lessons learned in implementing SCI clinical practice guidelines. SCI Nurs 2004;21:136-42.

190. Reynolds SS, Murray LL, McLennon SM, et al. Implementation of a Stroke Competency Program to improve nurses' Knowledge of and adherence to Stroke guidelines. J Neurosci Nurs 2016;48:328-35.

191. Rycroft-Malone J, Seers K, Chandler J, et al. The role of evidence, context, and facilitation in an implementation trial: implications for the development of the PARIHS framework. Implement Sci 2013;8:28.

192. Alleyne J, Jumaa MO. Building the capacity for evidence-based clinical nursing leadership: the role of executive co-coaching and group clinical supervision for quality patient services. J Nurs Manag 2007;15:230-43.

193. Hayes E, McCahon C, Panahi MR, et al. Alliance not compliance: coaching strategies to improve type 2 diabetes outcomes. J Am Acad Nurse Pract 2008;20:155-62.

194. Dilworth K, Tao M, Shapiro S, et al. Making health promotion evidenced-informed: an organizational priority. Health Promot Pract 2013:14:139-45.

195. Varnell G, Haas B, Duke G, et al. Effect of an educational intervention on attitudes toward and implementation of evidencebased practice. Worldviews Evid Based Nurs 2008;5:172-81.

196. Sacco TL, LaRiccia B. Interprofessional Implementation of a Pain/ Sedation Guideline on a Trauma Intensive Care Unit. $J$ Trauma Nurs 2016;23:156-64.
197. Hung DY, Glasgow RE, Dickinson LM, et al. The chronic care model and relationships to patient health status and health-related quality of life. Am J Prev Med 2008;35(5 Suppl):S398-S406

198. Shortell SM, Marsteller JA, Lin M, et al. The role of perceived team effectiveness in improving chronic illness care. Med Care 2004;42:1040-8.

199. Aagaard EM, Gonzales R, Camargo CA, et al. Physician champions are key to improving antibiotic prescribing quality. Jt Comm J Qual Patient Saf 2010;36:109-16.

200. Jeffers BR, Robinson S, Luxner K, et al. Nursing faculty mentors as facilitators for evidence-based nursing practice. J Nurses Staff Dev 2008;24:E8-E12.

201. Pepler CJ, Edgar L, Frisch S, et al. Strategies to increase researchbased practice: interplay with unit culture. Clin Nurse Spec 2006;20:23-31.

202. McCleary L, Ellis JA, Rowley B. Evaluation of the pain resource nurse role: a resource for improving pediatric pain management. Pain Manag Nurs 2004;5:29-36.

203. van der Zijpp TJ, Niessen T, Eldh AC, et al. A Bridge over Turbulent Waters: illustrating the interaction between Managerial leaders and facilitators when Implementing Research evidence. Worldviews Evid Based Nurs 2016;13:25-31.

204. Kousgaard MB, Thorsen T. Positive experiences with a specialist as facilitator in general practice. Dan Med J 2012;59:A4443.

205. Wright N. First-time knowledge brokers in health care: the experiences of nurses and allied health professionals of bridging the research-practice gap. Evidence \& Policy: A Journal of Research, Debate and Practice 2013;9:557-70.

206. Shifaza F, Evans D, Bradley H, et al. Developing evidencebased practice champions in the Maldives. Int J Nurs Pract 2013;19:596-602.

207. Stenger K, Schooley K, Moss L. Moving to evidence-based practice for pain management in the critical care setting. Crit Care Nurs Clin North Am 2001;13:319-27.

208. Hadjistavropoulos T, Williams J, Kaasalainen S, et al. Increasing the frequency and timeliness of Pain Assessment and Management in Long-Term Care: knowledge transfer and sustained implementation. Pain Res Manag 2016;2016:1-13.

209. Begley CM. Developing inter-professional learning: tactics, teamwork and talk. Nurse Educ Today 2009;29:276-83

210. Branowicki PA, Shermont H, Rogers J, et al. Improving systems related to clinical practice: an interdisciplinary team approach. Semin Nurse Manag 2001;9:110-4.

211. Routhieaux RL, Higgins SE. Best-practice guidelines for utilizing facilitators. Health Care Superv 1999;17:1-10.

212. Schwartz R. The skilled facilitator. San Francisco, CA: Jossey-Bass, 2002. 